Araştırma Makalesi/Research Article

\title{
Çanakkale'de IPARD Projesi Kapsamında Makine Ekipman Desteği Alan Üreticilerin Memnuniyet Düzeyini Etkileyen Faktörlerin Analizi
}

\author{
Sibel Tan $^{1 *} \quad$ Özge Ekinci $^{1}$ Hasan Kurt $^{1}$ Nurcan Karakoç$^{1}$ \\ ${ }^{1}$ Çanakkale Onsekiz Mart Üniversitesi, Ziraat Fakültesi, Tarım Ekonomisi Bölümü, 17020, Çanakkale. \\ *Sorumlu yazar: sibeltan@,comu.edu.tr
}

Geliş Tarihi: 15.04 .2018

Kabul Tarihi: 04.06.2018

\section{$\ddot{\mathbf{O} z}$}

Dünyada ve Türkiye'de artan nüfusa bağlı olarak artan gıda ihtiyacı tarımda ekstansif yerine entansif yaklaşımları gündeme getirmiştir. Teknolojinin tarıma tatbiki ile birim alandan ve birim hayvandan daha fazla verim elde etmeye dayalı entansif tarım yaklaşımında tarımda makine kullanımının önemi giderek artmaktadır. Bu durum Türkiye'de gerek ulusal fon kaynaklı gerekse uluslar arası fon kaynaklı kırsal kalkınma projelerinde makine ekipman alımı desteklemelerini gündeme getirmiş ve devlet politikası olarak benimsenmesinde etkili olmuştur. Bu desteklerle tarımsal faaliyette etkinlik ve verimliliği sağlamak üzere gerekli makine ekipmanı olmayan üreticilerin ihtiyaçlarının karşılanması veya sahip oldukları teknolojinin yenilenmesi hedeflenmiştir.

$\mathrm{Bu}$ araştırmanın popülasyonunu, Çanakkale İlinde Katılım Öncesi Mali Yardım Aracı Kırsal Kalkınma Bileşeni (Instrument for Pre-accession Assistance in Rural Development-IPARD) kapsamında, Çiftlik Faaliyetlerinin Çeşitlendirilmesi ve Geliştirilmesi Programı ile makine ve ekipman desteği alan üreticiler oluşturmaktadır. Araştırmada tesadüfi örnekleme yöntemiyle seçilen 100 üretici ile anket yapılmış bu üreticilerin demografik göstergeleri, işletme yapıları ve tarımsal varlıkları tespit edilmiştir. Ayrıca Lojistik Regresyon ile üreticilerin makine ekipman desteğinden memnuniyetlerini etkileyen faktörler analiz edilmiştir. Yapılan analiz sonucunda arazi büyüklüğü, makine ekipman alma kararlığı ve makine ekipman ile ilgili bir sorun yaşamama durumları pozitif yönde anlamlı çıkmıştır.

Anahtar Sözcükler: IPARD, Makine Ekipman Desteği, Çanakkale, Türkiye.

\section{Analysis of Factors Affecting the Satisfaction Level of Producers from Machinery- Equipment Support within the scope of the IPARD Project in Çanakkale}

\section{Abstract}

Growing food need has brought up intensive approaches in agriculture to the agenda instead of extensive approaches depending on the growing population in the world and Turkey. The use of machinery in agriculture has become increasingly important in the intensive farming approach based on increasing productivity per unit of field and animal with technology in agriculture. This situation has brought up machinery and equipment purchase support to the agenda within the scope of both the national fund based and international fund based rural development projects in Turkey and have influenced its adoption as government policy. In this study, the factors affecting utilization of machinery and equipment purchase support in the scope of the IPARD Project and Diversification and Development of Farm Activities Program in Çanakkale Province were analyzed. The data were determined by random sampling and were obtained by survey from a total of 100 firms who benefited from and did not benefit from the support. Survey results were used to identify demographic indicators, business practices and agricultural assets of producers. In addition, the Logistics Regression has analyzed the factors that affect manufacturers' satisfaction with machine equipment support. As a result of the analysis carried out, the size of the land, the determination of the machinery equipment and the problem of living with the machine equipment have become meaningful in the positive direction.

Keywords: IPARD, Machinery, Equipment, Support, Çanakkale, Turkey.

\section{Giriş}

Dünyada kırsal kesimde yaşayan toplumların kentte yaşayanlara göre olanaklarının daha sınırlı olması nedeniyle, bu insanların hayat standardını yükseltmek ve gelirlerini artırmak ülkelerin en temel sorunlarından birini oluşturmuş ve kırsal kalkınmanın sağlanmasına dönük farklı politika arayışları gündeme gelmiştir (Işık ve Baysal, 2011).

Günümüzde uygulanan kırsal kalkınma politikalarının hemen hemen tamamı Avrupa Birliği (AB) ile uyum sürecinde Ortak Tarım Politikası (OTP) kapsamında yürütülen uygulamalardır. Bu bağlamda OTP Avrupa Ekonomik Topluluğu'nun (AET) kuruluş yıllarından itibaren topluluğun en 
önemli politikalarından biri olmuştur. Kuruluş yıllarında OTP'nin amaçları tarımda verimliliği ve çiftçi gelir seviyesini artırmak iken zaman içerisinde OTP reform sürecine girmiş ve tarım politikaları kırsal kalkınma ve çevre korumaya dönük politikalara dönüşmüştür.

Ortak Tarım Politikasındaki reformlarla birlikte Türkiye'de de tarım politikalarında reform arayışları gündeme gelmiş, 7. ve 8. Kalkınma planlarında ilk reform sinyalleri verilmiştir. $\mathrm{Bu}$ planlarda daha rekabetçi bir tarım sektörü için Çiftçi Kayıt Sistemi (ÇKS), Tarım Sigortası Kanunun çıkarılması, kırsal kalkınma ve tarım sanayi entegrasyonun altı çizilmiştir (Yavuz, 2006).

Diğer taraftan kuruluş yıllarından itibaren ekonomik kalkınma bakımından, AB içindeki farklılıkları azaltmak birlik içindeki sosyal uyumu artırmak ve aday ülkelerin AB'ye uyumunu sağlamak üzere Avrupa Sosyal Fonu (ASF), Avrupa Bölgesel Kalkınma Fonu (ABKF), Avrupa Tarımsal Yönverme ve Garanti Fonu (AYGF) gibi fonlarla AB içinde bölgeler arası ve üye ülkeler arasındaki yapısal farklılıkları gidermeye çalışmıştır (Tan, 2009).

Türkiye-AB mali işbirliği ve OTP açısından son önemli adım Katılım Öncesi Mali Araçtır (IPA). $\mathrm{Bu}$ süreçte Türkiye'nin Avrupa Birliği'ne ( $\mathrm{AB}$ ) tam üyelik sürecinde $\mathrm{AB}$ mali yardım mekanizması yeniden tanımlanmış, AB mali yardımları "Katılım Öncesi Yardım Aracı (Instrument for Pre-Accession-IPA)" ile tek çatı altında ve tek bir hukuki çerçevede toplanmıştır. Beş bileşene sahip olan IPA'nın Kırsal Kalkınma Bileşeni (IPARD) çerçevesinde küçük ve orta ölçekli tarım işletmelerinin çeşitli fonlarla desteklenerek güçlendirilmesi ve rekabet şanslarının artırılabilmesi hedeflenmiştir (Tan ve Ark., 2008). Bu işletmelerin desteklenmesinde kurumsal olarak 4 Mayıs 2007 tarih ve 5648 sayılı kanun ile "Tarım ve Kırsal Kalkınmayı Destekleme Kurumlarının-TKDK" kurulmasına karar verilmiştir. Bu kurumların amacı ilgili kanunda; "Ulusal Kalkınma Plan, Program ve Stratejilerinde öngörülen ilke ve hedefler çerçevesinde, $A B$ ve uluslararası kuruluşlardan sağlanan kaynakları da kapsayacak şekilde, kırsal kalkınma programlarının uygulanmasına yönelik faaliyetleri gerçekleştirmek" olarak belirlenmiştir (Anonim, 2007).

Şu anda 42 ilde faaliyet gösteren TKDK'larda süt ürünleri, et ürünleri, su ürünleri, sebze meyve işleme, kırsal turizm gibi birçok konuda \%50'si hibe olmak üzere ekonomik yatırım projeleri desteklemektedir. Ayrıca Çiftlik Faaliyetlerinin Çeşitlendirilmesi ve Geliştirilmesi Programı kapsamında üreticilere en az 5.000 EURO en fazla 500.000 EURO olmak üzere yatırımların \%50'si hibe olmak şartıyla makine ekipman desteği sağlanmaktadır (Anonim, 2018).

Dünyadaki nüfus artışı ile birlikte tarımsal üretimde birim alandan ve birim hayvandan daha fazla verim alma zorunluluğu insanoğlunu ekstansif tarımdan entansif tarıma yönlendirmiştir. Entansif tarım daha fazla teknolojinin ve makine ekipman kullanımının olduğu bir modeldir.

Bir ülke veya bir bölgedeki kırsal kesimin sosyo-ekonomik gelişim düzeyinin artırılması, tarımsal üretimde yeni ve modern teknolojilerin kullanılmasıyla mümkündür. Mekanizasyon; ileri teknolojilerin uygulanmasını, ayrıca toprak, su, gübre, ilaç, ve diğer girdilerin etkin kullanımını olanaklı kılarak tarımda verimliliği sağlayan önemli bir üretim aracıdır. Kalkınmış ülkelerin tarımında, verimlilikte sağlanan gelişmelerin tümünde mekanizasyon anahtar rol oynamıştır. Küresel rekabet ortamında bu rol kuşkusuz giderek artan önemle sürecektir (Evcim ve ark., 2009).

Çanakkale'de TKDK il Koordinatörlüğ̈̈ aracıllı̆ı ile ilçeler itibariyle toplam 202 üretici IPARD kapsamında makine ekipman desteklerinden faydalanmıştır (Ayvacık 9, Bayramiç 33, Biga 63, Çan18, Eceabat 1, Ezine 16, Gelibolu 5, Gökçeada 2, Lapseki 3, Merkez 32 ve Yenice 20) (Anonim, 2016).

Dolayısıyla bu araştırmanın amacı IPARD Programı kapsamında Çanakkale TKDK İl Koordinatörlüğü aracılığı ile makine ekipman desteği alan üreticiler ile ilgili genel bilgiler incelenmiş ve üreticilerin aldığ desteklerden memnuniyet durumunu etkileyen faktörlerin analizi yapılmıştır.

\section{Materyal ve Yöntem}

Araştırmanın ana materyalini Çanakkale İlinde ilçeler itibariyle TKDK'dan makine ekipman desteği alan üreticilerle yüz yüze yapılan anket sonuçları oluşturmuştur. Ayrıca konuyla ilgili daha önce yapılmış olan ulusal ve uluslararası çalışmalar, başta TUíK ve TKDK olmak üzere diğer ulusal ve uluslararası istatistik kuruluşlarından elde edilen veriler ikincil veriler olarak kullanılmıştır. Makine ekipman desteği alan üreticilerin tam listesi ve iletişim numaraları Çanakkale TKDK İl Koordinatörlüğünden alınmıştır. Çanakkale ilinde destekten faydalanan 202 üretici araştırmanın popülasyonunu oluşturmaktadır. Örnek hacminin belirlenmesinde basit tesadüfi örnekleme yöntemine göre aşağıdaki formül kullanılmıştır (Yamane, 1967). 
$\mathrm{n}=\left[\mathrm{N} \cdot \mathrm{S}^{2} \mathrm{x}\right] /\left[(\mathrm{N}-1) \cdot \mathrm{D}^{2}\right]+\mathrm{S}^{2} \mathrm{x}$

$\mathrm{n}$, örneğe çıkan işletme sayısı

$\mathrm{N}$, popülasyondaki işletme sayısı,

$\mathrm{S}^{2} \mathrm{x}, \mathrm{x}$. derecedeki standart sapma,

$\mathrm{D}^{2}=\mathrm{d}^{2} / \mathrm{z}^{2}$

$\mathrm{d}=$ popülasyon ortalamasından izin verilen hata miktarı,

$\mathrm{z}=$ izin verilen güvenlik sınırının standart normal dağılım tablosundaki değeridir.

Araştırmada, anket uygulanacak işletme sayısının belirlenmesinde $\% 10$ hata payı ve $\% 90$ güvenilirlikle çalışılmıştır. Yukarıda belirtilen formüle göre örnek sayısı 100 olarak hesaplanmış ve ilçelere göre dağılımı oransal olarak yapılmıştır. Araştırma alanında örneğe giren her işletme yöneticileri ile doldurulan anketler ayrı ayrı gözden geçirilerek gerekli kontrol ve hesaplamalar yapılmış ve veriler SPSS paket programlarına aktarılarak ortalamalar, yüzdeler ve Lojistik Analizi yöntemleri kullanılmıştır.

\section{Bulgular ve Tartışma}

Üreticiler Ille Ilgili Genel Bilgiler

Araştırma kapsamında anket yapılan üreticilerin yaş aralıkları ve ortalamaları Çizelge 1'de verilmiştir. Üreticilerin \%49'u 29-47 yaşları arasında \%51'i ise 48-56 yaşları arasındadır. Anket yapılan üreticilerin yaş ortalaması 47,7 olarak hesaplanmıştır.

Çizelge 1. Anket yapılan kişilerin IPARD projelerinden nasıl haberdar oldukları bilgisi

\begin{tabular}{|c|c|c|c|}
\hline Yaș (Yıl) & & Sayı & $(\%)$ \\
\hline $29-47$ & & 49 & 49,0 \\
\hline $48-66$ & & 51 & 51,0 \\
\hline En küçük:29 & En büyük:66 & Ort: 47,7 & \\
\hline
\end{tabular}

Üreticilerin aile içindeki konumları Çizelge 2'de verilmiştir. Bu kapsamda anket yapılan üreticilerin \%93'ü erkek aile reisi \%5'i aile reisinin eşi, \%2'si ise evin erkek çocuğudur. Bu değerler projelerin hedef kitlesi olan kadın ve genç nüfusun alınan alet ekipman ve kullanılan destek konusunda çok fazla söz sahibi olmadığını göstermektedir.

Çizelge 2. Anket yapılan üreticinin ailedeki konumu

\begin{tabular}{lrr}
\hline Aile İçi Statü & Sayı & $\mathbf{( \% )}$ \\
\hline Aile reisi (Koca) & 93 & 93,0 \\
Aile reisinin eşi (Kadın) & 5 & 5,0 \\
Ailenin erkek çocuğu & 2 & 2,0 \\
Toplam & 100 & 100,0 \\
\hline
\end{tabular}

Araştırma kapsamında anket yapılan üreticilerin eğitim durumları Çizelge 3'de gösterilmiştir. Çizelgeye göre makine ekipman desteği alan üreticilerin büyük çoğunluğu ilk ve ortaokul mezunu (\%59), ikici sırada lise mezunu (\%28), üçüncü sırada ise üniversite mezunu gelmektedir (\%6). Anket yapılan üreticilerden sadece bir tanesi okuma yazma bilmemekte, 6 kişi ise herhangi bir okula gitmediği halde okuma yazma bilmektedir.

Çizelge 3. Anket yapılan üreticinin eğitim durumu

\begin{tabular}{lrr}
\multicolumn{1}{c}{ Eğitim Seviyesi } & Sayı & $\mathbf{( \% )}$ \\
\hline Okuma yazma bilmeyen & 1 & 1,0 \\
Okula gitmemiş ama okuma yazma bilen & 6 & 6,0 \\
İlkokul ve ortaokul mezunu & 59 & 59,0 \\
Lise mezunu & 28 & 28,0 \\
Üniversite mezunu & 6 & 6,0 \\
Toplam & 100 & 100,0 \\
\hline
\end{tabular}

Araştırma sonuçlarına göre üreticilerin tarımsal faaliyet yapma konusundaki deneyimleri yıl olarak çizelge 4'de gösterilmiştir. Üreticilerin $\% 45$ 'i 20 yıldan daha az bir deneyime, $\% 55$ 'i ise $\% 20$ 
yıldan daha fazla deneyime sahip olduğunu ifade etmiştir. Araştırma sonuçlarına göre anket yapılan üreticiler için ortalama deneyim yaklaşık 27 yıl civarında hesaplanmıştır.

Araştırma kapsamında üreticilerin kaç yıldan beri bulundukları köyde ikamet ettikleri çizelge 5'de gösterilmiştir. Üreticilerin \%42'si 5-43 yıldır, \%58'i ise 44-66 yıldan beri aynı köyde ikamet ettiklerini ifade etmişlerdir. Anket yapılan üreticilerin köyde ikamet etme sürelerinin ortalamas 143,42 olarak hesaplanmıştır.

Çizelge 4. Anket yapılan üreticinin tarımsal faaliyet deneyimi



Anket yapılan üreticilerin halen köylerinde ikamet edip etmediği sorulmuştur. Üreticilerden \%80'i halen köyünde ikamet ettiğini \%20'si etmediğini ifade etmiştir. Bu durum verilen desteklerde hedef kitlenin kırsal kesimde yaşayanlar olması açısından olumlu bir bulgudur.

Çizelge 6. Anket Yapılan Üreticilerin Tüm Yıl Köyde İkamet Etme Durumu

\begin{tabular}{lrrr}
\multicolumn{1}{c}{ İkamet Durumu } & Sayı & $(\%)$ & \\
\hline İkamet edenler & & 80 & \\
İkamet etmeyenler & 20 & 20,0 \\
Toplam & 100 & & 100,0 \\
En küçük:2 En büyük:12 Ort:75000 Standart sapma:2,65832 & & & \\
\hline
\end{tabular}

Araştırma kapsamında anket yapılan üreticilerin sosyal güvencelerinin olup olmadığ çizelge 7'de gösterilmiştir. Anket sonuçlarına göre üreticilerin \%93'ü herhangi bir sosyal güvenceye sahip olduğunu ifade ederken sadece 7 kişi herhangi bir sosyal güvencesi olmadığını belirtmiştir.

Çizelge 7. Anket yapılan üreticilerin sosyal güvence durumu

\begin{tabular}{lrr}
\hline Sosyal Güvence Durumu & Sayı & $\mathbf{( \% )}$ \\
\hline Var & 93 & 93,0 \\
Yok & 7 & 93,0 \\
Toplam & 100 & 100,0 \\
\hline
\end{tabular}

Üreticilerin tarım dışı gelir durumları çizelge 8 'de gösterilmiştir. Buna göre üreticilerin \%36'sının tarım dışı herhangi bir geliri bulunduğu, \%64'ünün ise tarım dışı geliri bulunmadığı ifade edilmiştir.

Çizelge 8. Anket yapılan üreticilerin tarım dışı gelir durumu

\begin{tabular}{lrr}
\hline Tarım Dışı Gelir Durumu & Sayı & $\mathbf{( \% )}$ \\
\hline Var & 36 & 36,0 \\
Yok & 64 & 64,0 \\
Toplam & 100 & 100,0 \\
\hline
\end{tabular}

Tarım dışı geliri olduğunu belirten üreticilerin gelir kaynakları çizelge 9'da gösterilmiştir. Anket yapılan üreticilerin \%11,1'i emeklilikten, \%63,9'u esnaflıtan, \%25,0'i ise serbest faaliyetlerden gelir elde ettiklerini ifade etmiştir.

Çizelge 9. Üreticilerin tarım dışı gelir kaynakları

\begin{tabular}{lrr} 
Tarım Dışı Gelir Kaynağı & Sayı & $\mathbf{( \% )}$ \\
\hline Emekli & 4 & 11,1 \\
Esnaf & 23 & 63,9 \\
\hline
\end{tabular}




\begin{tabular}{lrr}
\hline Serbest & 9 & 25,0 \\
Toplam & 36 & 100,0 \\
\hline
\end{tabular}

Araştırma kapsamında incelenen destek konusu arazi varlığı ve arazilerin parçalılık durumu ile direk alakalıdır. Anket yapılan üreticilerin işledikleri arazilerin mülkiyet durumu ve bu arazilerin parça sayıları çizelge 10 'da gösterilmiştir. Anket yapılan üreticilerin verdiği cevaplara göre 77 üretici sulu mülk arazisine sahip olduğunu, bu arazilerin ortalama işletme genişliğinin 60,2 da, parça sayısının ise ortalama 4,9 parçadan olduğu belirlenmiştir.

Çizelge 10. Mülkiyetlerine göre arazi varlığı ve parça sayısı

\begin{tabular}{|c|c|c|c|c|c|}
\hline \multicolumn{6}{|c|}{ Mülk Arazi Varlığı ve Parça Sayısı } \\
\hline & En Küçük & En Büyük & Ortalama & $\begin{array}{c}\text { Standart } \\
\text { Sapma }\end{array}$ & $\begin{array}{l}\text { Üretici } \\
\text { Sayısı }\end{array}$ \\
\hline Sulu alan(da) & 4 & 300 & 60,2 & 56,8 & 77 \\
\hline Sulu alan parça sayısı & 1 & 20 & 4,9 & 3,8 & \\
\hline Kuru alan(da) & 4 & 200 & 49,7 & 42,3 & 59 \\
\hline Kuru alan parça sayısı & 1 & 20 & 5,0 & 3,6 & \\
\hline \multicolumn{6}{|c|}{ Ortakçı Arazi varlığı ve Parça Sayısı } \\
\hline Sulu alan(da) & 50 & 150 & 100,0 & 70,7 & 2 \\
\hline Sulu alan parça sayısı & 4 & 13 & 8,5 & 6,4 & \\
\hline Kuru alan(da) & 20 & 50 & 35,0 & 21,2 & 2 \\
\hline Kuru alan parça sayısı & 2 & 10 & 6,0 & 5,6 & \\
\hline \multicolumn{6}{|c|}{ Kiracı Arazi varlığı ve Parça Sayısı } \\
\hline Sulu alan(da) & 5 & 300 & 60,3 & 52,3 & 59 \\
\hline Sulu alan parça sayısı & 1 & 16 & 5,4 & 3589,0 & \\
\hline Kuru alan (da) & 10 & 220 & 58,4 & 46,3 & 48 \\
\hline Kuru alan parça sayısı & 1 & 20 & 6,3 & 4,6 & \\
\hline
\end{tabular}

Aynı şekilde 59 üretici kuru mülk araziye sahip olduğunu belirtmiş, bu arazilerin ortalama genişliği 49,7 dekar parça sayısı ise ortalama 5 parça olarak belirlenmiştir. Sulu alanda ortakçılık yaptığını ifade eden 2 üreticinin verdiği cevaplara göre ortalama işletme genişliği 100 dekar, parça sayısı 8,5 olarak belirlenmiştir. Yine kuru alanda ortakçılık yapıldığını 2 üretici belirmiş olup ortalama işletme genişliği 35 dekar parça sayısı ise 6 olarak belirlenmiştir.

Sulu anada kiracılık yaptığını belirten 59 üreticinin beyanlarına göre ortalama işletme genişliği 60 dekar, ortalama parça sayısı ise 5,4 olarak belirlenmiştir. Yine kuru alan kiraladığını belirten 48 üreticiye göre ortalama işletme genişliği 46,3 dekar parça sayısı ise 4,6 olarak tespit edilmiştir.

IPARD Projesi İle İlgili Bulgular

Araştırma kapsamında anket yapılan kişilerin IPARD projelerinden haberdar olma durumu çizelge 11 'de gösterilmiştir. Çizelgeye göre üreticilerin $\% 8$ ' üretici/satıc1 firma tarafından $\% 26$ 's1 tanıdık ve yakın çevresinden \%64'ü Gıda, Tarım ve Hayvancılık Bakanlığı İl ve İlçe Müdürlüklerinin duyurusu ile, \%2'si diğer bilgi kaynaklarından haberdar olduğunu ifade etmiştir.

Çizelge 11. Anket yapılan kişilerin IPARD projelerinden nasıl haberdar oldukları bilgisi

\begin{tabular}{lrr}
\hline Haber Kaynă̆ı & Sayı & (\%) \\
\hline Üretici veya satıcı firma & 8 & 8 \\
Tanıdık ve yakın çevre & 26 & 26 \\
GTHB il ve ilçe müdürlükleri & 64 & 64 \\
Diğer & 2 & 2 \\
Toplam & 100 & 100 \\
\hline
\end{tabular}

Destekleme kapsamında toplam 202 üretici makine ekipman desteklerinden faydalanmıştır. Bu üreticiler programdan toplam 267 adet makine ekipman temin etmiştir. Çizelgeye 12'ye göre IPARD 
Projesi Çiftlik Faaliyetlerinin Çeşitlendirilmesi ve Geliştirilmesi Programı kapsamında Traktör (94), Pulluk (55), Römork (40) gibi çiftlik aletleri en fazla tercih edilmiştir. Dinlendirme kazanı, bal süzme aleti, sır alma tezgahı gibi daha spesifik ekipmanlar ise daha az sayıda tercih edilen alet ekipmanlardır.

Çizelge 12. Program kapsamında üreticilere verilen makine ekipman

\begin{tabular}{lrr}
\hline Ekipman & Ekipman sayıs & (\%) \\
\hline Traktör & 94 & 35,2 \\
Pulluk & 55 & 20,6 \\
Römork & 40 & 15,0 \\
Diskaro & 17 & 6,4 \\
Pülverizatör & 14 & 5,2 \\
Kazayağı & 8 & 3,0 \\
Rotavatör & 7 & 2,6 \\
Gübre serpme & 7 & 2,6 \\
Tırmı & 6 & 2,2 \\
Çapa makinesi & 5 & 1,9 \\
Mibzer & 5 & 1,5 \\
Patlatma & 3 & 1,1 \\
Freze & 2 & 0,7 \\
Dinlendirme kazanı & 1 & 0,4 \\
Bal süzme aleti & 1 & 0,4 \\
Sir alma tezgahı & 1 & 0,4 \\
Mum eritme & 1 & 0,4 \\
Aysan & 1 & 0,4 \\
Toplam & 267 & 100,0 \\
\hline
\end{tabular}

Üreticilere aldığı makine ekipman ile ilgili fiyat araştırması yapıp yapmadığı sorulmuştur. Üreticilerin \%92'si piyasa araştırması yaptığını, \%8'i ise yapmadığını ifade etmiştir. Diğer taraftan aldıkları makine ekipmanların fiyatlarını piyasa fiyatlarıyla mukayese etmeleri istenmiştir. Üreticilerin $\% 57$ 'si piyasa fiyatı ile aynı, $\% 21$ 'i piyasa fiyatından daha ucuz, \%18'i piyasa fiyatından daha pahalı olduğunu ifade etmişlerdir. Anket yapılan üreticilerin \%8'i ise fiyat araştırması yapmadığı için bu konuda bir fikri olmadığını ifade etmiştir (Çizelge 13).

Çizelge 13. Temin edilen alet ekipmanın piyasa fiyatı ile mukayese edilmesi durumu

\begin{tabular}{lrr} 
Kriter & Sayı & $\mathbf{( \% )}$ \\
\hline Aynı fiyat & 55 & 55,0 \\
Daha ucuz & 20 & 20,0 \\
Daha pahalı & 17 & 17,0 \\
Fikrim yok & 8 & 8,0 \\
Toplam & 100 & 100,0 \\
\hline
\end{tabular}

Araştırma kapsamında anket yapılan üreticilere IPARD desteği ile makine ekipman almadan önce çiftlik faaliyetlerindeki ihtiyaçlarını karşılama durumları sorulmuştur. Buna göre üreticilerin \%58'i ihtiyaçlarını yakınlarının ekipmanlarını kullanarak karşıladığını, \%26'sı kendi ekipmanlarını kullandığını, \%10'ihtiyaçlarını karşılayamadıklarını, \%6'sı ise kiralama yoluyla karşıladıklarını ifade etmiştir (Çizelge 14).

Çizelge 14. Makine ekipman desteği almadan önce ihtiyaçların karşılanma durumu

\begin{tabular}{lrr}
\hline Kriter & Sayı & (\%) \\
\hline Yakınlarımın ekipmanlarını kullanma & 58 & 58,0 \\
\hline
\end{tabular}




\begin{tabular}{lrr}
\hline Kendi ekipmanlarını kullanma & 26 & 26,0 \\
İhtiyaçları karşılayamama & 10 & 10,0 \\
Kiralama & 6 & 6,0 \\
Toplam & 100 & 100,0 \\
\hline
\end{tabular}

Üreticilerin destek kapsamında aldığı makine ekipmanın ihtiyaçlarını karşılama durumu incelendiğinde üreticilerin \%66'sı ihtiyaçlarının tamamen karşılandığını, \%30'u kısmen karşılandığını, \%4'ü ise ihtiyaçlarının hiçbir şekilde karşılanmadığını belirtmiştir (Çizelge 15).

Çizelge 15. Makine ekipman alındıktan sonra ihtiyaçların karşıılanma durumu

\begin{tabular}{lrr}
\hline Kriter & Sayı & $\mathbf{( \% )}$ \\
\hline İhtiyaçlarını tamamen karşılıyor & 66 & 66,0 \\
İhtiyaçlarını kısmen karşı1ıyor & 30 & 30,0 \\
İhtiyaçlarını hiç karşımlamıyor & 4 & 4,0 \\
Toplam & 100 & 100,0 \\
\hline
\end{tabular}

Anket yapılan üreticilere IPARD destekleri kapsamında makine ekipman aldıktan sonra üretim artış1 olup olmadığ1 sorulduğunda üreticilerin \%87'si üretim artışı olduğunu \%13'ü ise herhangi bir üretim artışı olmadığını ifade etmiştir (Çizelge 16).

Çizelge 16. Makine ekipman alındıktan sonra üretim artışı olup olmama durumu

\begin{tabular}{lrr}
\hline Kriter & Sayı & (\%) \\
\hline Evet & 87 & 87,0 \\
Hayır & 13 & 13,0 \\
Toplam & 100 & 100,0 \\
\hline
\end{tabular}

Üreticilerin Memnuniyetlerini Etkileyen Faktörlerin Analizi

Lojistik Regresyon analizinde modelinin bağımlı değişkeni, IPARD kapsamında alınan makine ekipmanlardan memnuniyet durumudur. (1: Memnun, 0: Memnun değil). Likelihood ratio test sonucu, modelin istatistiki olarak geçerli olduğunu göstermektedir $\left(\mathrm{X}^{2}: 22.478, \mathrm{p}: 0.0325\right)$.

Çizelge 18. Makine desteği alan üreticilerin ihtiyaçlarını karşılamalarını etkileyen faktörlerin analizi

\begin{tabular}{lllll}
\hline Değişkenler & Katsayı & Std. Hata & p-Değeri & Ĕğim \\
\hline Sabit & -104.062 & 459.383 & 0.02350 & \\
Yaş & 0.0398964 & 0.0378422 & 0.29175 & 0.00854429 \\
Eğitim & -0.514723 & 0.439712 & 0.24176 & -0.110234 \\
Çiftçilik deneyimi & -0.0421656 & 0.028192 & 0.13474 & -0.00903027 \\
Tarım dışı gelir & 0.0117157 & 0.48871 & 0.98087 & 0.00250907 \\
Arazi miktarı & 0.0117083 & 0.00385354 & $0.00238^{* * *}$ & 0.00250747 \\
Fiyat araştırması yapma & 0.496694 & 100.781 & 0.62212 & 0.106373 \\
Tarımsal üretimde artış & 198.595 & 0.778079 & $0.01070^{* *}$ & 0.425314 \\
Sorunla karşılaşma & 178.672 & 0.985494 & $0.06983^{*}$ & 0.382647 \\
Krediyle satın alma düşüncesi & 0.699547 & 0.511836 & 0.17171 & 0.149816 \\
Makine ekipmanı kiralama düşüncesi & 0.811269 & 0.867366 & 0.34962 & 0.173743 \\
\hline
\end{tabular}

Analiz sonucuna göre; Arazi miktarı ile IPARD makine ekipman desteğinden memnun olma durumu arasında istatistiki olarak anlamlı bir ilişki bulunmuştur. Arazi miktarının yüzer yüzer artması bu destekten memnuniyet eğilimini \%25 artırmaktadır. Makine ekipman desteğinden sonra çiftçilerin tarımsal üretimlerinde artış olup olmaması ile IPARD makine ekipman desteğinden memnuniyet durumu arasında istatistiki olarak anlamlı bir ilişki bulunmuştur. Buna göre tarımsal üretimde artış oldu diyenler \%42 daha fazla desteklerden memnun olma eğilimindedirler. Makine ekipman 
desteğinden faydalanırken herhangi bir sorun yaşamayanların, desteklerden memnuniyet eğilimleri $\% 38$ daha fazladir.

\section{Sonuç ve Öneriler}

Yapılan araştırmadan elde edilen bulgular incelendiğinde, üreticilerin çiftçilik deneyimi, uzun süredir köylerinde ikamet etmeleri, arazi büyüklükleri, alınan alet ekipmanlara olan ihtiyaç desteklerin amacına ulaşması açısından olumlu bulgular olarak tespit edilmiştir. Diğer taraftan ortalama üretici yaşı, destek alınan alet ekipmanın bireysel olarak temini, modern tarım teknolojisi yerine klasik teknolojik tarım alet ve makinelerinin tercihi proje amaçları açısından olumlu olmayan bulgulardır. Yine yapılan regresyon analizinden elde edilen sonuçlara göre arazi büyüklügü, makine ekipman alma kararlığı ve makine ekipman ile ilgili bir sorun yaşamama durumları pozitif yönde anlamlı çıkmıştır.

$\mathrm{Bu}$ bulgulardan yola çıkarak bu kapsamda verilen destekler için genç ve kadın nüfusun daha fazla teşvik edilmesi, bireysel kullanım yerine kolektif kullanımın teşviki ile kaynak israfının önlenmesi önerilebilir. Bu konuda tarımsal amaçlı kooperatifler, üretici birlikleri ve diğer üretici örgütlerinin proje ve fonlarla ilgili farkındalık düzeyi artırılmalıdır. Diğer taraftan klasik alet ekipman yerine yenilikçi ürün ve ekipmanların kullanımının sağlanan fonlarla yaygınlaştırılması önemli bir öneri olarak sunulabilir.

Not: Bu çalışma, “TÜBİTAK 2209/A Üniversite Öğrencileri Yurt İçi Araştırma Projeleri Destek Programı" kapsamında yürütülen bir projeden üretilmiştir. Proje Başvuru No: 1919B011502619.

\section{Kaynaklar}

Anonim, 2007. Kırsal Kalkınmayı Destekleme Kurumu Kuruluş ve Görevleri Hakkında Kanun, 4/5/2007 Tarih ve 5648 Sayll Resmi Gazete.

Anonim, 2016.TKDK Çanakkale İl Koordinatörlüğü Verileri, Çanakkale.

Anonim, 2018. http://www.tkdk.gov.tr/AltTedbir/ciftlik-faaliyetlerinin-cesitlendirilmesi-ve-gelistirilmesi.

Evcim, Ü., E., Ulusoy, E., Gülsoylu, B., Tekin, 2009. Tarımsal mekanizasyon durumu, sorunları ve çözüm önerileri. TMMOB Ziraat Mühendisleri Odası Yayınları, Ankara.

Işık, N., Baysal, D., 2011. Avrupa Birliği’ne uyum sürecinde Türkiye'de kırsal kalkınma politikaları:genel bir değerlendirme. Cumhuriyet Üniversitesi İktisadi ve İdari Bilimler Fakültesi Dergisi, Cilt:12.s.165. Sivas.

Tan, S., Kumuk, T., Aktürk, D., 2008. Küçük ve orta ölçekli gıda işletmelerinin gelişimi için kullanılabilecek $\mathrm{AB}$ fonları ve $\mathrm{AB}$ hibe projeleri. VIII. Ulusal Tarım Ekonomisi Kongresi, s:234-244, 25-28 Haziran, Bursa.

Tan, S., 2009. Tarım Reformu uygulama projesi kapsamında kırsal kalkınma projeleri: Çanakkale ili köy bazlı katılımcı yatırım programı örneği. Girişimcilik ve Kalkınma Dergisi, 4(2):51-62. Çanakkale.

Yamane, T, 1967. Elementary sampling theory. Publisher: Englewood Cliffs, N.J., Prentice-Hall.

Yavuz, F., 2006. Türkiye'de tarım politikaları s.43-67 Editör: F. Yavuz. Türkiye'de Tarım. T.C. Tarım ve Köyişleri Bakanlığı, Strateji Geliştirme Başkanlığı, Ankara. 